\title{
Poesia infantil e transitoriedade do leitor criança
}

\author{
Maria da GLória Bordini \\ UFRGS/CNPq
}

\begin{abstract}
RESUMO: PRETENDE-SE UMA DISCUSSÃO SOBRE A POESIA PARA CRIANÇAS, BEM COMO A TRANSITORIEDADE QUE CARACTERIZA TAL TIPO DE LEITOR, ALÉM DE ATIVIDADES PARA A FORMAÇÃO DO GOSTO POÉTICO EM TAL FASE DO DESENVOLVIMENTO HUMANO.
\end{abstract}

ABSTRACT: IT IS A DISCUSSION ON POETRY FOR CHILDREN, AND THE TRANSIENCE THAT CHARACTERIZES THIS TYPE OF PLAYER, AND ACTIVITIES FOR THE FORMATION OF POETIC TASTE IN THIS PHASE OF HUMAN DEVELOPMENT.

PALAVRAS-CHAVE: LEITOR CRIANÇA - POESIA - POESIA INFANTIL KEY-WORDS: CHILD READER - POETRY - NURSERY RHYMES 
transitoriedade intrínseca da poesia infantil constitui ao mesmo tempo a maior dificuldade nas atividades relacionadas com a formação do leitor jovem e a condição-chave para o êxito das etapas de iniciação e fixação do gosto pelo poético. Como toda a literatura infanto-juvenil, a poesia também se define pelo estatuto etário de seu recebedor, o que determina estágios de desenvolvimento cognitivo-afetivo e patamares em escala crescente de experiência existencial, que possibilitem a identificação do texto com o leitor, chave para o sucesso da leitura (cf. ZILBERMAN, 1986: 21). Essa característica do leitor a quem se destina o poema infanto-juvenil se reflete sobre a estrutura textual, afetando procedimentos estéticos e tratamento temático. Há, em conseqüência, poemas para crianças pequenas, poemas para crianças maiores e poemas para pré-adolescentes, com estatutos próprios e correspondentes a expectativas e necessidades das diferentes idades de seus leitores.

Seguir a evolução natural do desenvolvimento da criança e do jovem na proposição de leituras adequadas deveria, em vista disso, resolver os futuros obstáculos da formação do gosto pela poesia, que repercutem no leitor adulto, em geral infenso ao gênero. Todavia, a questão não é simples. Em primeiro lugar, a infância atual se acelera dia-a-dia em termos de maturação. Em conseqüência, os produtores de poesia infanto-juvenil percebem com dificuldade os interesses rapidamente mutáveis e as limitações psicobiológicas inumeravelmente variáveis de seus recebedores numa sociedade de desníveis sociais. A tentativa de conformar as estruturas textuais às habilidades crescentes das crianças e jovens em cada faixa etária se torna um desafio, ainda mais levando em conta que os poetas apresentam melhores poemas quanto mais estes estejam vinculados à sua experiência pessoal e cultural, que é a de um adulto. Além disso, precisam preocupar-se com sua própria visão de infância e adolescência, a qual deveria, para ter os efeitos emancipatórios da grande arte, subverter o universo jovem com o qual desejam se comunicar (cf. BORDINI, 1986).

Não é imotivada a presença forte da poesia de origem folclórica nas primeiras faixas etárias (cf. OPIE; OPIE, 1979), depois retrabalhada para escolares das séries iniciais. De um lado, a poesia erudita não dedica poemas para serem lidos pela família ao bebê e ao infante. Restam, pois, aqueles que a própria família recebe da tradição popular. Por outro lado, quando as crianças chegam à escola, a poesia erudita lhes oferece a matéria folclórica já conhecida, mais estilizada, garantindo para si os muito jovens iniciantes. 
Da quinta à oitava série, entretanto, quando os padrões folclóricos já foram esgotados do ponto de vista do consumidor criança, a produção erudita vacila, retomando estruturas incompatíveis com o estágio de maturação de seu leitor. Em vez de explorar os recursos não folclóricos, ou de reinventar os de origem popular, tende a infantilizar os textos e, com isso, os afasta da clientela já mais voltada para o mundo. A poesia folclórica deixa de ser fonte, porque o universo infantil vai se desligando da esfera familiar para a escolar, e as manifestações populares, provenientes de camadas desprivilegiadas, parecem desimportantes tanto à criança maior, mais voltada para o racionalismo imperante na sociedade burguesa, quanto à escola, que só pensa, quando o faz, no esquadro erudito.

Um bom poema, entretanto, um poema esteticamente eficaz, não deveria sofrer esse processo de desgaste formal e temático. Se os padrões artísticos - mesmo dentro de suas determinações espaço-temporais - fossem priorizados pela sociedade, qualquer texto, dirigido a qualquer faixa etária, valeria como experiência estética indefinidamente. Poder-se-ia dizer que, nesse caso, a poesia infanto-juvenil perdura enquanto seus textos conseguem não apenas afetar leitores de diferentes idades, mas também manter com eles algum tipo de intercâmbio significativo, no plano do prazer ou no da autoconsciência (cf. a idéia de efeito e interação, em ISER, 1979: 83). Seria por esse caminho que o poema superaria sua transitoriedade estrutural e atingiria foros de arte literária.

A questão não dispensa, contudo, as diferenças de desenvolvimento. $\mathrm{Na}$ verdade, um bebê não pode "ler" Cecília Meireles. Uma criança de quatro anos não entende a graça de um poema-piada. Uma criança de oito anos não se interessa por poesia de denúncia social. Isso não quer dizer que aos quatro, oito ou doze anos, as crianças não apreciem poemas destinados às faixas anteriores. O problema todo está em desconsiderar o estatuto estruturalmente adaptativo do poema infanto-juvenil, como se o jovem não estivesse em constante mudança das habilidades lingüísticas e da bagagem experiencial que são o requisito básico para que compreenda e ame o poema em qualquer estágio de seu desenvolvimento.

Nos dias que correm, em que a produção de poesia infantil deve se adequar ao mercado, uma vez que é a indústria cultural que possui os meios de produção para atingir a massa de leitores-crianças e adolescentes, a situação do poeta se agrava. Ele precisa buscar sua inserção num mercado editorial para atingir seu público e esse mercado lhe devolve feições que se esvaecem à 
medida que ele parece alcançá-lo. O aspecto etário obstaculiza o ato criativo em alguém que já não se defronta com mutações pessoais tão aceleradas e radicais e isso afeta a criação, já que a poesia moderna é intensamente subjetiva e que a subjetividade mutante do leitor jovem desorienta o poeta que a visa.

A necessidade não apenas mercadológica, mas estrutural, da adaptação de temas e recursos formais para a situação etária do leitor infantil e juvenil pode gerar produtos poéticos pouco duráveis, mal resolvidos, mas sem dúvida é fator dominante na mobilização dos procedimentos compositivos e linguísticos do poema destinado à criança e ao jovem (cf. ZILBERMAN \& MAGALHÃES, 1982: 19). Não pode, portanto, ser desconsiderada sob o argumento de que "o poema bom vale sempre", porque, além de ser o ponto de referência para aquisição e oferta de livros de poesia ao público infanto-juvenil, operando discriminações e rejeições, participa da própria estruturação do texto e atinge em seu cerne a relação comunicativa entre discurso poético adulto e mundo da infância e adolescência.

Importa, em vista desses argumentos, que a seleção dos textos poéticos oferecidos ao jovem no lar e na escola não se faça por critérios externos, provenientes da psicologia ou da pedagogia, das conveniências sociais ou morais, mas pelos fenômenos internos ao próprio texto, a que o leitor infanto-juvenil reage positiva ou negativamente. Para Glória Pondé,

A poesia, portanto, seria um dos meios de se escapar do imperialismo do poder adulto, centrado na razão e na linearidade, para se atingir outros processos de leitura e/ou de ver o mundo. Esta seria uma forma de libertação da leitura detalhista e discursiva para uma leitura mais pictórica, em que a palavra tenta voltar-se para a coisa em si. (PONDÉ, 1986: 128)

O impressionante poder da poesia de restituir "a coisa em si" requer uma análise textual cuidadosa, que privilegie o poema enquanto construção poética, não enquanto peça literária que atende os interesses ideológicos de pais e professores, editores, livreiros e críticos literários. Como adverte Ligia Averbuch (1991: 76): “O poema é um discurso fechado formando um universo de linguagem, reinventando a cada vez suas regras. $\mathrm{O}$ 'desmontar' do texto poético significa compreender estas regras, não em sua teoria, mas em sua evidência prática, na realidade da estrutura verbal organizada”. 
Também está implícita nessa análise textual a observação das reações do leitor jovem aos procedimentos construtivos e às proposições temáticas, verificando-se o que, no texto, produz experiência estética, prazer da descoberta, ao lado daquilo que induz à indiferença ou à rejeição. Hans Robert Jauss, o expoente da Estética da Recepção alemã, não desprezava a pesquisa da "história dos efeitos" para discutir a força emancipatória da literatura (cf. JAUSS, 1979: 55). Sua posição se coaduna com a de Cecília Meireles, que valorizava, na relação de leitura, antes a apropriação infantil do poema do que o dever de lê-lo. Dizia ela, em tom de invocação:

Ah, tu, livro despretensioso, que, na sombra de uma prateleira, uma criança livremente descobriu, pelo qual se encantou, e, sem figuras, sem extravagâncias, esqueceu as horas, os companheiros, a merenda... tu, sim, és um livro infantil, o teu prestígio será, na verdade, imortal. (MEIRELES,1979: 28)

É evidente que Cecília ainda não vivia numa sociedade de consumo exasperada como a atual, em que se fazem sempre mais necessárias estratégias de conquista de leitores contra a hegemonia da produção estandardizada, mas é transparente sua tese: a literatura só se torna infantil quando consagrada pelas crianças no processo histórico, passando, pois, a fazer parte do imaginário da infância. Nessa linha de pensamento, poucos poemas sobreviveriam, da produção atual, por vezes repetitiva e pouco instigante, ou despovoada de temas e figuras que empolguem a fantasia e o desejo de verdade do público infantil.

Nessas condições, é preciso pensar numa possível hierarquização da produção poética para jovens que leve em conta as habilidades lingüísticas e intelectuais requeridas pelos textos, a partir de suas características estruturais e do horizonte de expectativas e aspirações que estas originam, cotejado com desejos e restrições impostos pelo horizonte sociohistórico das crianças e adolescentes. Uma tal hierarquização é útil para orientar a oferta de textos respeitando os diferenciais de cada faixa etária de leitores em formação, desde que não seja entendida como uma camisa-de-força que impeça o jovem de se movimentar pelo universo poético de acordo com sua própria iniciativa.

Nos quadros a seguir, organizados por faixas etárias bastante restritas, aparecem os gêneros mais comuns da poesia infantil. Esses gêneros são descritos através dos componentes estruturais, temático-formais, esperados pelo leitor- 
jovem de cada faixa etária, conforme a tradição histórica da poesia infanto-juvenil autoriza a inferir. Essas características são acompanhadas de uma avaliação esquemática das habilidades lingüísticas que pressupõem, das operações intelectuais que requerem e de uma indicação sumária do contexto social cotidiano que cerca o consumo desses gêneros. Os critérios principais são, pois, o receptor-mirim ou jovem e suas expectativas (obtidas através da análise da história da poesia infantil e de uma pesquisa-diagnóstico - cf. ZILBERMAN \& BORDINI, 1989: 193-227) e os textos poéticos por ele comprovadamente consumidos nas diversas etapas de seu desenvolvimento, que se comprovam pela permanência das obras no mercado editorial.

Esses quadros, como quaisquer outros, por sua feição classificatória, podem ser confundidos com um receituário para a seleção de textos por pais e professores. Seu propósito, porém, não é orientar o consumo e sim refletir relações prováveis entre a poesia e a criança e o adolescente, em termos de aspirações estéticas e padrões de gosto. Nele busca-se reproduzir, numa disposição seqüencial por faixa etária de zero a quatorze anos, equivalente ao estágio de formação da criança antes da adolescência, as marcas que a transitoriedade do leitor imprime sobre os gêneros poéticos. O levantamento de aspectos compositivos e temáticos mostra as diferenças tanto de expectativas quanto de execução do poema em função dessa transitoriedade.

\section{Critérios para atender à transitoriedade do leitor de poesia infantil}

- Faixa etária: 1-2 anos.

- Gênero: Brincos; acalantos.

- Características textuais: rima; ritmo cadenciado; verso regular; paralelismos sonoros e sintáticos; homologia entre criança e mundo animal ou entre partes do corpo infantil e toque corporal rítmico.

- Habilidades lingüísticas requeridas: Percepção auditiva da cadeia fônica.

- Operações intelectuais pressupostas: Autopercepção corporal; associação toque-sonoridade-ritmo.

- Contexto/Ações: Lar. Cuidados com o bebê. 
- Faixa etária: 2-4 anos.

- Gênero: Quadrinhas; parlendas; lenga-lengas.

- Características textuais: Forte aliteração e assonância, paralelismos sonoros e sintáticos, rima fixa, verso regular, refrões, ritmos fixos e repetitivos, ilogismo semântico, descrição cômica de fatos do cotidiano infantil, descrição lírica de animais e coisas animadas, teor fantástico.

- Habilidades lingüísticas requeridas: Reconhecimento de padrões melódicos; percepção de semelhanças fônicas; fixação de padrões sintáticos repetitivos; percepção de níveis suprafrasais breves.

- Operações intelectuais pressupostas: Percepção fragmentária do mundo, com lacunas lógicas; pensamento egocêntrico.

- Contexto/Ações: Lar / Narração de histórias curtas; brinquedos cantados entre pais e filhos.

- Faixa etária: 4-5 anos.

- Gênero: Lenga-lengas; parlendas; quadrinhas; cantigas de roda; retratos; abecedários; continas.

- Características textuais: Verso regular; rima variada; paralelismos sintáticos e sonoros; ritmos encadeados e compassados; descrição cômica de pessoas e tipos sociais; heróis desajeitados; transmissão de saberes (letras, números, fatos históricos, meteorologia, vida, normas tradicionais).

- Habilidades lingüísticas requeridas: Associação significante-significado; associação signo-referente-contexto; autonomia entre linguagem e mundo; percepção de níveis suprafrasais médios

- Operações intelectuais pressupostas: Percepção mágica do mundo; compreensão da separação entre pensamento e mundo; formação de conceitos concretos; formação de valores de socialização.

- Contexto/Ações: Lar; vizinhança; pré-escola / Brinquedos cantados entre crianças.

- Faixa etária: 5-6 anos.

- Gênero: Quadrinhas; parlendas; adivinhas; trava-línguas; cantigas de roda; poemas líricos.

- Características textuais: jogo aliterativo e assonante; rima rica; verso regular; ritmos encadeados; utilização de figuras de linguagem (metáfora e meto- 
nímia); ênfase na experimentação semântica (plano lexical e plano sintático); subversão da lógica; mundo das possibilidades - o "Mundo do Se".

- Habilidades lingüísticas requeridas: Prolação adequada; associação do signo a mais de um referente; percepção de processos de significação mais complexos: organização paradigmática e sintagmática (semelhanças/contrastes e contigüidades).

- Operações intelectuais pressupostas: Percepção mágica do mundo; relações entre pensamento e mundo governadas pelo desejo; busca de nexos causais (porquês); capacidade de conversão; capacidade de dedução.

- Contexto/Ações: Lar; vizinhança; pré-escola / Rivalidades grupais; brinquedos cantados.

- Faixa etária: 7-8 anos.

- Gênero: Quadrinhas; parlendas; adivinhas; trava-línguas; cantigas de roda; poemas líricos, baladas, apólogos; poemas-piada; trocadilhos; poemas absurdos (nonsense).

- Características textuais: Paralelismo sonoro e sintático; rima; versos regulares e livres; versos brancos; refrões; estrofes curtas; jogos de idéias; ênfase na regularidade sintática e não fônica; ênfase na narratividade; enredos lineares; aventuras (tragicômicas); heróis tolos; heróis animais; seres fantásticos; heróis valentes.

- Habilidades lingüísticas requeridas: Percepção de níveis supra frasais longos; transformação de sentidos em representações imaginárias; apreensão de estruturas narrativas; percepção de contra-sensos.

- Operações intelectuais pressupostas: Percepção menos egocêntrica do mundo; percepção dos nexos causais; percepção de processos temporais; domínio da espacialidade.

- Contexto/Ações: Lar; vizinhança; escola / Brinquedos cantados.

- Faixa etária: 9-10 anos.

- Gênero: Poemas-piada; desafios; épica aventuresca; apólogos; baladas; lírica social.

- Características textuais: Verso livre; ritmos livres e irregulares; ênfase na imagética; ênfase na narratividade; enredos lineares; lírica descritiva; en- 
foque cômico; enfoque sério; heróis animais e humanos; heróis valentes; heróis comuns; heróis engraçados; heróis desportivos.

- Habilidades lingüísticas requeridas: Relacionamento linguagem-mundo; concretização de sentidos suprafrasais.

- Operações intelectuais pressupostas: capacidade lógico-dedutiva; pensamento não-egocêntrico; formação de esquemas conceituais; formação de esquemas de valores socialmente aceitos; interesses extrovertidos.

- Contexto/Ações: Lar; comunidade; escola / Leitura pessoal.

- Faixa etária: 10-12 anos.

- Gênero: Épica social ou histórica; épica mitológica; lírica social; lírica amorosa; epigramas; baladas; canções; poemas humorísticos.

- Características textuais: Rima ou verso branco; verso livre; ritmo livre e semântico; presença de narrativas; lirismo subjetivo; lírica descritiva; lírica reflexiva; lírica social; heróis aventurescos ou derivados dos gêneros de massa; heróis-crianças comuns; heróis-adultos incomuns; comicidade; temas amorosos, lendários, urbanos, desportivos.

- Habilidades lingüísticas requeridas: Relacionamento linguagem-ficçãomundo; interpretação da linguagem figurada.

- Operações intelectuais pressupostas: Capacidade de análise descritiva; pensamento formal; formação de esquemas conceituais; formação de esquemas de valores próprios.

- Contexto/Ações: Lar; comunidade pré-adolescente; escola / Leitura pessoal.

- Faixa etária: 12-14 anos.

- Gênero: epigramas; odes; canções; sonetos; poemas de forma livre; poemas humorísticos ou satíricos; haicais; lírica amorosa; lírica narrativa; lírica social e reflexiva

- Características textuais: Ritmos livres e evocativos; versos rimados ou brancos; estrofes curtas, mas poemas mais longos; paralelismos ocultos; riqueza imagética; maior presença de lacunas textuais; teor descritivo, introvertido, reflexivo/teor narrativo, extrovertido, sociológico; temas cômicos, aventurescos, psicológicos, amorosos, biográficos. 
- Habilidades lingüísticas requeridas: Percepção estética dos processos lingüísticos artísticos; relacionamento de isomorfias e isotopias; interpretação dos implícitos.

- Operações intelectuais pressupostas: Pensamento formal; capacidade de análise descritiva e lógica; formação de esquemas conceituais; transformação de esquemas conceituais; formação de hierarquias de valores; crítica de valores.

- Contexto/Ações: Lar; comunidade adolescente; escola / Leitura pessoal.

O exame desses quadros revela que, na medida do crescimento intelectual e lingüístico infantil, o poema passa do jogo de puras sonoridades para o jogo de conteúdos, ou seja, para os gêneros não mais folclóricos, mas clássicos, a épica aventuresca e a lírica amorosa e reflexiva, com uma curiosa busca, pelos leitores maiores, de textos de ação física como os de temática desportiva. Isso lembra as odes pindáricas, voltadas para a exaltação da perfeição física e moral do atleta, espécie de poesia que nunca vingou no Ocidente pós-medieval, em virtude do obscurecimento da visão do corpo como fonte de prazer, substituída pela visão do corpo como máquina de guerra, nas canções épico-lendárias.

Outro aspecto marcante é que, para as faixas etárias de zero a oito anos, há variados exemplos dos gêneros propostos. Quando se ultrapassam os nove anos, o acervo disponível se torna menos fértil, não abrange a maior parte das possibilidades históricas de consumo e dá preeminência ao intimismo, quando as faixas etárias estão, no processo de desenvolvimento, mais interessadas na descoberta do mundo, na ação sobre ele. Pode-se observar claramente que as preferências temáticas, obtidas através de pesquisa de campo, não encontram ressonância na poesia lírica produzida para esses receptores, que têm, por isso, um atendimento a apenas uma das esferas de sua maturação, a emocional, em que a introspecção ainda se encontra em germe.

Essas defasagens entre o que é possível oferecer e o que interessa ao universo infanto-juvenil devem ser levadas em conta por todos aqueles que trabalham em favor da formação do gosto pela poesia, seja no âmbito familiar, escolar, comunitário ou da indústria cultural. Evidentemente essas indicações não são diretivas, estão sujeitas a ampla discussão, mas constituem matéria para orientar a tomada de decisões na área da produção e consumo da poesia infantil brasileira. 
A poesia, entre as artes literárias, é a que menos leitores conquista para si, apesar da quantidade de poetas que se lançam ao mercado pela via das editoras ou em edições pessoais. Não são apenas as dificuldades de comercialização, a falta de divulgação ou o silêncio da crítica a que cabe a responsabilidade pela paisagem árida no campo da poesia. O poema é uma estrutura altamente organizada, cujos elementos não só interagem entre si, mas também com o mundo extraliterário (cf. LOTMAN, 1978). A leitura de poesia, em conseqüência, mobiliza uma série complexa de habilidades subjetivas e culturais que não acontece sem a educação estética, hoje tão negligenciada. Levar em consideração a transitoriedade do leitor jovem, na proposição de textos poéticos à infância, é um dos caminhos para a promoção de uma mais produtiva fruição do texto poético.

\section{Referências Bibliográficas}

AVERBUCH, Ligia. A poesia e a escola. In: ZILBERMAN, Regina (Org.). Leitura em crise na escola: as alternativas do professor. 10. ed. rev. e atual. Porto Alegre: Mercado Aberto, 1991.

BORDINI, Maria da Glória. Poesia infantil. São Paulo: Ática, 1986.

ISER, Wolfgang. A interação do texto com o leitor. In: LIMA, Luiz Costa (Org.). A literatura e o leitor. Rio de Janeiro: Paz e Terra, 1979.

JAUSS, Hans Robert. A Estética da Recepção: colocações gerais. In: LIMA, Luiz Costa (Org.). A literatura e o leitor. Rio de Janeiro: Paz e Terra, 1979.

LOTMAN, Iuri. A estrutura do texto artístico. Lisboa: Estampa,1978.

MEIRELES, Cecília. Problemas da literatura infantil. 3. ed. São Paulo: Summus; Brasília: INL, 1979.

OPIE, Iona; OPIE, Peter (Ed.). The Oxford nursery rbyme book. Oxford: Oxford University Press, 1979.

PONDÉ, Glória Maria Fialho. Poesia para crianças: a mágica da eterna infância. In: KHÈDE, Sonia Salomão (Org.). Literatura infantil: um gênero polêmico. Porto Alegre: Mercado Aberto, 1986.

ZILBERMAN, Regina. O lugar do leitor na produção e recepção da literatura infantil. In: KHÈDE, Sonia Salomão (Org.). Literatura infantil: um gênero polêmico. Porto Alegre: Mercado Aberto, 1986.

ZILBERMAN, Regina; BORDINI, Maria da Glória (Coord.). Guia de leitura para alunos de $1^{\circ}$. e $2^{\circ}$. graus. São Paulo: Cortez; Brasília: INEP, 1989.

ZILBERMAN, Regina; MAGALHÃES, Ligia Cademartori. Literatura infantil: autoritarismo e emancipação. São Paulo: Ática, 1982. 